\title{
Cervical kyphoscoliosis
}

\section{Cifoescoliosis cervical}

\section{Sandeep Khanna ${ }^{\mathrm{a}}$ (D), Sergio Bustamante ${ }^{\mathrm{b}}$ (D)}

a Department of Cardiothoracic Anesthesiology, Department of General Anesthesiology and Department of Outcomes Research, Anesthesiology Institute, Cleveland Clinic Foundation. Ohio, USA.

${ }^{\mathrm{b}}$ Department of Cardiothoracic Anesthesiology, Anesthesiology Institute, Cleveland Clinic Foundation. Ohio, USA.

Correspondence: Department of Cardiothoracic Anesthesiology, Department of Ceneral Anesthesiology and Department of Outcomes Research, Anesthesiology Institute, Cleveland Clinic Foundation. 9500 Euclid Avenue, E3-108, Cleveland Clinic Foundation, Cleveland, Ohio 44122. E-mail: khannas@ccf.org

How to cite this article: Khanna S, Bustamante S. Cervical kyphoscoliosis. Colombian Journal of Anesthesiology. 2021;49:e948.

Cervical kyphoscoliosis is an uncommon spinal deformity. Kyphosis or outward curvature of cervical-spine (Image A) has led to a fixed flexion state resulting in suspension of patient's head in the air while lying on the imaging table. Additionally, dextroscoliosis or rightward convexity of the cervical vertebral axis has resulted in a persistent leftward head tilt (Image B). Head and neck radiation and trauma can lead to cervical kyphoscoliosis. In addition to the cosmetic deformity, patients present with myelopathic sensorimotor symptoms such as weakness and tingling of upper extremities. The Poisson effect states that flexion of the spine lengthens and stretches the spinal canal, reduces its area and narrows its lumen. This causes spinal cord impingement and myelopathy.(1)

An anterior-posterior surgical approach is often needed for deformity correction. Inability to achieve the 'sniffing" position, laryngeal shift away from the midline and limited neck extension, make airway management challenging, often necessitating an awake fiber-optic intubation. $(1,2)$ Invasive arterial monitoring and large-bore vascular access are essential in view of possible prolonged surgical duration and heightened risk of profuse bleeding. In conjunction with prone position, these conditions confer a higher risk for perioperative vision loss, warranting a preoperative discussion with patients.
IMAGE A. Kyphosis or outward curvature of cervical-spine.

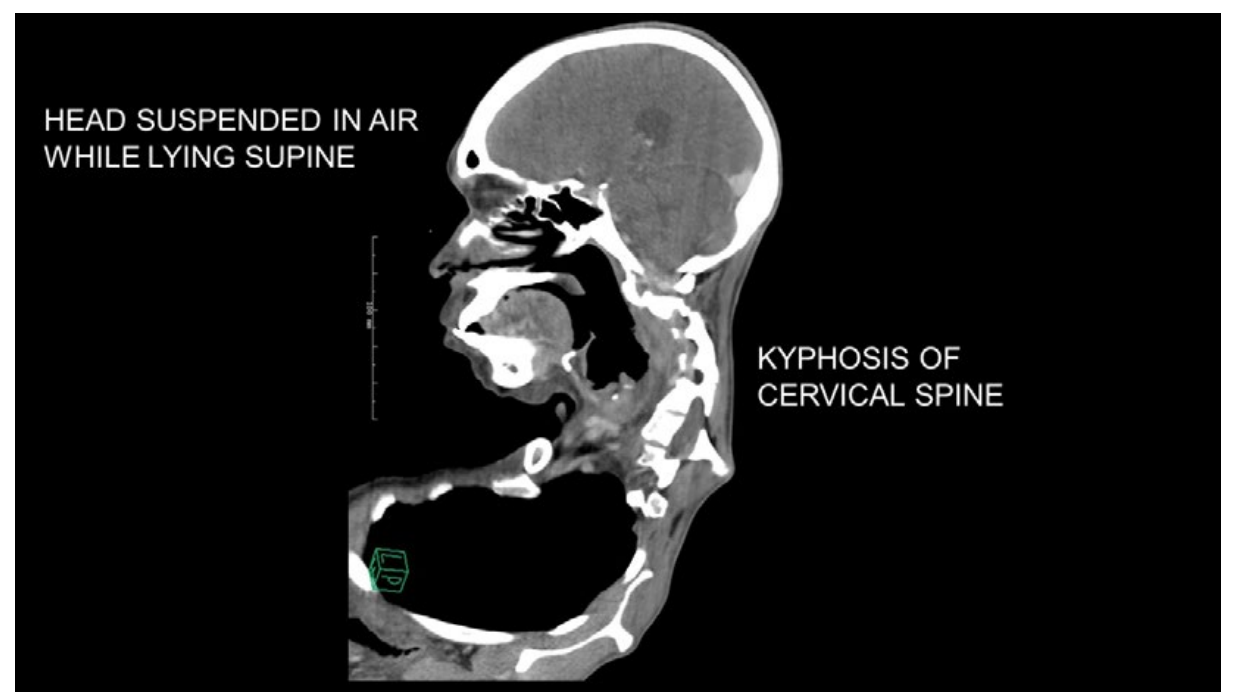

SOURCE: Authors.

IMAGE B. Dextroscoliosis or rightward convexity of the cervical vertebral axis.

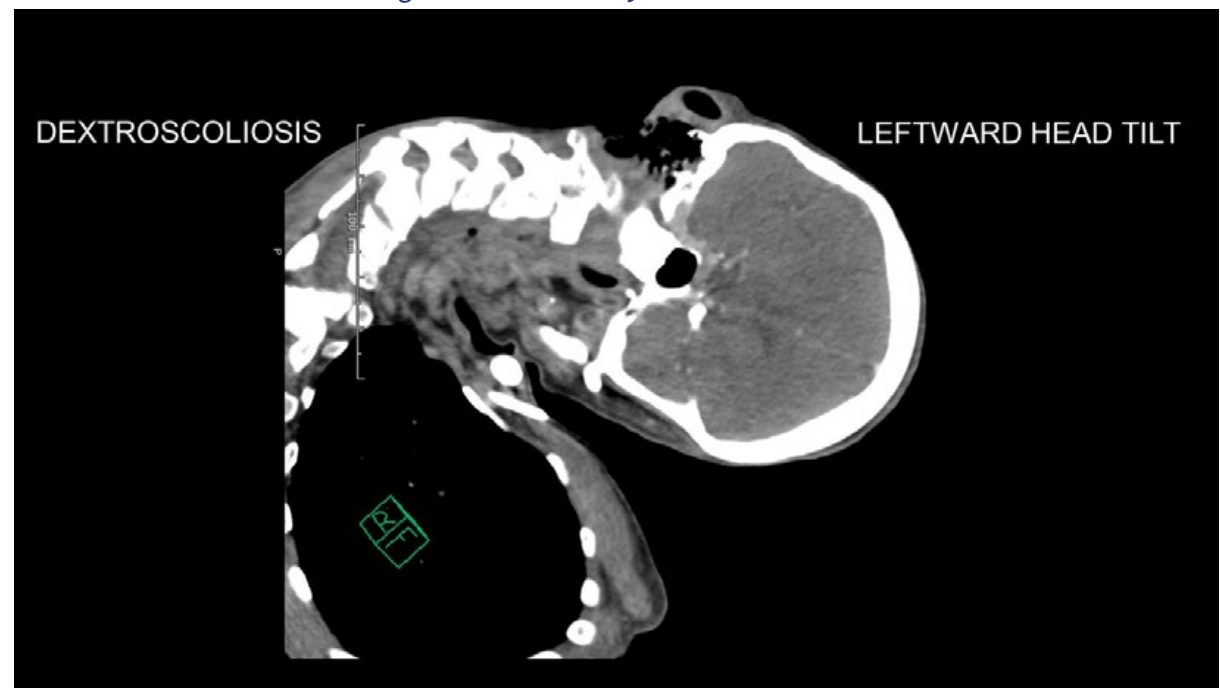

SOURCE: Authors.

Lea la versión en español de este artículo en www.revcolanest.com.co

Copyright (C) 2021 Sociedad Colombiana de Anestesiología y Reanimación (S.C.A.R.E.)

This is an open access article under the CC BY-NC-ND license (http://creativecommons.org/licenses/by-nc-nd/4.0/). 
In addition to avoiding direct pressure on the eyes, positioning the head at or above the level of the heart may help decrease risk of vision loss. Although reverse Trendelenburg maneuver aids in achieving appropriate head positioning, it increases risk of venous air embolism.(3) Propofol and remifentanil infusions facilitate evoked potential monitoring without interfering with signal acquisition or interpretation while vasopressor infusions may be required to maintain systemic and spinal cord perfusion. It is prudent to delay extubation after prolonged surgery. Airway distortion from edema and potential cervical hematoma can render ventilation via a mask or supraglottic device ineffective and hamper re-intubation efforts. $(1,4)$

\section{ACKNOWLEDGEMENTS}

\section{Author's contributions}

SK: Conception of project, planning and final writing of manuscript.
SB: Conception of project, approval of manuscript.

\section{Assistance with the study}

None declared.

\section{Financial support and sponsorship}

None declared.

\section{Conflicts of interest}

None declared.

\section{Presentation}

None declared.

\section{REFERENCIAS}

1. Crosby ET, Warltier DC. Airway Management in Adults after Cervical Spine Trauma. Anes- thesiology 2006;104:1293-318. doi: https://doi. org/10.1097/00000542-200606000-00026.

2. Kirksey MA, Haskins SC, Soffin EM, Liu SS: Anesthesia for Orthopedic Surgery, Clinical Anesthesia, 8th edition. Edited by Barash PG, Cullen BF, Stoelting RK, Cahalan MK, Stock MC, Ortega R, Sharar SR, Holt NF: Clinical Anesthesia, 8th edition. Philadelphia, Lippincott-Raven Publishers, 2017, pp 1442-7.

3. Practice Advisory for Perioperative Visual Loss Associated with Spine Surgery 2019: An Updated Report by the American Society of Anesthesiologists Task Force on Perioperative Visual Loss, the North American Neuro-Ophthalmology Society, and the Society for Neuroscience in Anesthesiology and Critical Care. Anesthesiology 2019;130(1):12-30. doi: https://doi.org/10.1097/ ALN.0000000000002503.

4. Palumbo MA, Aidlen JP, Daniels AH, Bianco A, Caiati JM. Airway compromise due to laryngopharyngeal edema after anterior cervical spine surgery. J Clin Anesth 2013;25:66-72. doi: https://doi.org/10.1016/j.jclinane.2012.06.008. 